\title{
SISTEMA DE AUTOMAÇÃO DO TESTE DE CONSISTÊNCIA DO CONCRETO SEGUNDO NORMA NBR - NM67
}

\section{AUTOMATION SYSTEM OF THE CONCRETE CONSISTENCY TEST ACCORDING TO STANDARD NBR - NM67}

\author{
Simoni Maria Gheno \\ Felipe Chiaratto ${ }^{\mathrm{II}}$ \\ Brendo Michelan de Lima ${ }^{\text {III }}$ \\ Bruno Giorgenon Silva ${ }^{\mathrm{IV}}$ \\ Gustavo J. Giardini Lahr ${ }^{\mathrm{V}}$
}

\begin{abstract}
RESUMO
Este trabalho visa a elaboração de um projeto de mecanização do teste da consistência do concreto pelo abatimento do tronco de cone, normalizado pela ABNT NBR NM-67. A consistência do concreto fresco é de suma importância no alcance da resistência final desejada e durabilidade após o processo de endurecimento e, por isso, amostras de todos os lotes devem ser verificadas antes da descarga em obra. Contudo a realização do teste é composta por técnicas rudimentares, sendo assim, passível a erros operacionais que prejudicam o resultado do teste. Neste contexto são aplicadas técnicas de mecanização, que simulam as movimentações do operador, e melhorias estruturais que garantem melhores condições de trabalho. O método proporcionará a padronização das operações com aumento da qualidade e precisão do teste.
\end{abstract}

Palavras-chave: Mecanização. Abatimento. Consistência.

Data de submissão do artigo: 12/09/2019.

Data de aprovação do artigo: 01/10/2019.

DOI:

\begin{abstract}
This work aims to elaborate a project of mechanization of the concrete consistency test by the reduction of the cone trunk, normalized by ABNT NBR NM-67. The consistency of the fresh concrete is of paramount importance in achieving the desired final resistance and durability after the hardening process and, therefore, samples of all batches must be checked before discharge into work. However, the realization of the test is composed of rudimentary

I Profa. Dra. da Faculdade de Tecnologia (FATEC) de Sertãozinho - SP - Brasil. Email: simoni.gheno@cps.sp.gov.br

II Engenheiro Mecânico formado pela Universidade Paulista de Ribeirão Preto - SP - Brasil. Email: felipe.chiaratto@gmail.com

III Engenheiro Mecânico formado pela Universidade Paulista de Ribeirão Preto - SP - Brasil. Email: brendo.michelan@live.com

IV Engenheiro Mecânico formado pela Universidade Paulista de Ribeirão Preto - SP - Brasil. Email: bruno.giorgenon@gmail.com

v Prof. Ms. da Universidade Paulista de Ribeirão Preto - SP - Brasil. Email: gustavo.lahr@docente.unip.br
\end{abstract}




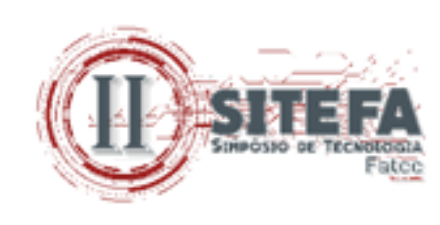

techniques, being thus susceptible to operational errors that impair the result of the test. In this context, mechanisation techniques are applied, simulating operator movements, and structural improvements that guarantee better working conditions. The method will provide standardization of the operations with increased quality and accuracy of the test.

Keywords: Mechanization. Abatement. Consistency.

\section{INTRODUÇÃO}

Atualmente, a situação da indústria da construção no Brasil apresenta ainda um grande desperdício advindo de falhas devidas tanto da utilização de técnicas arcaicas, quanto da falta de preparo da mão de obra. O uso de técnicas arcaicas justifica-se pelo fato de a indústria brasileira da construção civil manter-se muito conservadora, tornando a implementação de novas tecnologias um grande desafio. Em muitos casos os processos mais tecnológicos não são complementares ao processo em vigor, pois a utilização dessa tecnologia adiciona tarefas separadas do processo em si. (CIVIL; FREITAS, 2015)

Comparada a outros setores industriais que já possuem competitividade internacional e produtos de boa qualidade, a indústria da construção civil brasileira mantém-se estagnada, utilizando processos praticamente artesanais e técnicas rudimentares. Entretanto, com a intitulada "mecanização dos canteiros", inovação que vem sendo implementada, principalmente nos últimos anos, tem produzido resultados notáveis quanto a "redução no desperdício de materiais, melhoria geral da produtividade, possibilitando o aumento na escala de produção e redução dos preços de venda" (MENIN, 2012). Para Gama Lins de Araújo et al. (1983), o Brasil tem apresentado grande desenvolvimento de novas tecnologias voltadas à execução de obra, sendo que $57 \%$ deste desenvolvimento deve-se apenas ao melhoramento de equipamentos.

O gerente de produto da divisão construção da Atlas Copco Brasil, Schimidt, (2015) em entrevista para a Revista Manutenção e Tecnologia afirma que "a mecanização é um processo irreversível, não para substituição da mão de obra, mas para dotar a construção civil de opções que reduzam os tempos de execução, incrementem a precisão e garantam elevado nível de segurança". Entre inúmeras definições para mecanização e automação pode-se afirmar que se trata de uma técnica de otimização da padronização, visando economia e agilidade, substituindo em partes a mão de obra sendo necessária somente a supervisão. (CIVIL; FREITAS, 2015).

A consistência e trabalhabilidade do concreto fresco são de vital importância para a plena resistência, estabilidade do volume e durabilidade após o processo de endurecimento. Para o alcance de tais propriedades, o concreto fresco deve ter consistência tal que a sua compactação permita o seu transporte e execução sem que haja segregação (NEVILLE; BROOKS, 2010).

$\mathrm{O}$ concreto fresco não possui resistência estrutural, ao chegar à obra é possível observar somente a viscosidade a partir do qual é caracterizada sua consistência. Essa propriedade deve ser verificada antes da descarga do concreto em obra, para que haja aceitação dele. A verificação deve ocorrer em todas as betoneiras seguindo o método de ensaio descrito na Norma Brasileira NM 67: Concreto - Determinação da consistência pelo abatimento do tronco de cone (Slump Test) (CARROMEU et al., 2011).

O objetivo é o de especificar um método que determine a consistência do concreto fresco através da medida de seu assentamento, em laboratório e obra. $\mathrm{O}$ ensaio de abatimento 


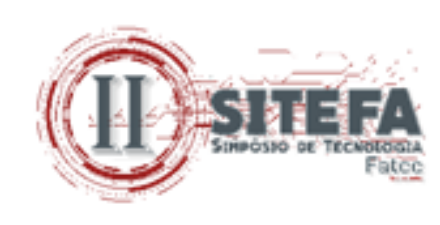

deve ser realizado em três etapas, sendo elas o preenchimento do cone em três camadas iguais, a compactação de cada camada através de 25 golpes da haste de compactação, onde toda a superfície da camada deve ser golpeada atentando-se para que os golpes não penetrem a camada subsequente. A segunda etapa consiste na retirada do molde do concreto, cuidadosamente, na direção vertical, sendo que a operação de retirar o molde deve ser realizada entre $5 \mathrm{~s}$ a $10 \mathrm{~s}$, com um movimento constante para cima, sem submeter o concreto a movimentos de torção lateral. Após a retirada do molde, deve-se determinar a diferença de altura entre o molde e o eixo do corpo de prova, obtendo-se o abatimento do concreto (ABNT NBR NM 67, 1998).

Após análise da execução do teste é possível perceber que os métodos são estritamente manuais. Sabe-se que este fato agregado a outros fatores pode resultar em tempo ocioso de mão de obra e equipamento e, também, retrabalho comprometendo a qualidade (GAMA LINS DE ARAÚJO et al., 1983). Sendo assim, propõe-se a mecanização do teste de consistência do concreto pelo abatimento do tronco de cone, afim de elevar a qualidade e precisão do processo, além de proporcionar melhores condições ergonômicas, sem que se perca a facilidade e mobilidade que a forma manual de execução possibilita, além de, adequar todos os processos mecanizados à Norma Regulamentadora.

\section{CONCRETO}

O concreto é um dos principais materiais utilizados na indústria da construção civil, ele se caracteriza pela mistura de cimento, água e agregados (cascalho ou brita e areia), em proporções exatas para determinados fins. Para cada utilização, o concreto é preparado de forma que as suas características finais, como por exemplo, a resistência, esteja condizente com a necessidade exigida.

A resistência final do concreto tem relação estreita com o seu grau de adensamento, ou seja, o quão homogêneo e sem a presença de vazios o concreto aparenta. Os vazios são bolhas de ar aprisionadas entre as partículas dos agregados após o processo de cura do concreto. A cura é caracterizada pelo período em que todo o excesso de água presente na estrutura leva para evaporar completamente, após esse processo o concreto em estado endurecido obtém sua resistência final (NEVILLE, 2015).

Neville (2010) estudou a relação entre a resistência e densidade (massa específica) do concreto e verificou que a massa específica relativa é diretamente proporcional à resistência relativa. $\mathrm{O}$ autor ainda afirma que a presença de vazios na massa de concreto pode diminuir consideravelmente a sua resistência final, estimou que 5\% de vazios podem diminui-la em até $30 \%$.

O devido adensamento do concreto se dá, além da boa execução no momento da concretagem, através das propriedades adquiridas em seu estado fresco. Uma das principais propriedades do concreto fresco é a consistência, a ACI 116R - 90, a define como "a mobilidade relativa ou capacidade de fluir do concreto ou argamassa". A capacidade do concreto de se deformar é correspondente à consistência e varia principalmente conforme a quantidade de água adicionada e a granulometria dos agregados (CARVALHO; FIGUEIREDO FILHO, 2010; NEVILLE, 2015). Com base na determinação da consistência, o concreto pode ser classificado em três grupos principais: seco ou úmido, plástico e fluido. Essa classificação fornece o grau de mobilidade do concreto, ou seja, a sua capacidade de escoar entre os aços que compõem a armadura das estruturas de concreto armado sem que haja segregação dos componentes ou comprometimento da homogeneidade da mistura 


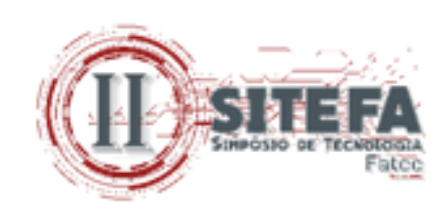

(GUIMARÃES, 2005). O item cinco da Norma Brasileira ABNT NBR 8953 - Concreto para fins estruturais - Classificação pela massa específica, grupos de resistência e consistência, apresenta classes de consistência e aplicações típicas de cada concreto de acordo com seu abatimento. (ABNT NBR 8953, 2015).

Conhecer exatamente a consistência do concreto é fundamental, pois cada aplicação tem suas características que necessita de parâmetros específicos, nesse caso não pode haver falhas ou essas devem ser minimizadas o máximo possível. Parisotto (2003), analisou as estimativas paramétricas de quantificação de custos de obras de edificações residenciais e identificou que para uma área total de $8916,93 \mathrm{~m}^{2}$, são necessários em média $0,368 \mathrm{~m}^{3} / \mathrm{m}^{2} \mathrm{de}$ concreto. A obra estudada apresentou custo total de $\mathrm{R} \$ 6156895,15$ sendo $\mathrm{R} \$ 656821,06$ destinados às despesas com concreto, ou seja, aproximadamente 10,67\%. Portanto, percebe-se a importância da realização de testes que proporcionem resultados confiáveis e exatos, para que não haja falhas e custos adicionais indevidos.

A consistência do concreto fresco é mensurada através do ensaio de Abatimento do Tronco de Cone, normalizado pela Norma Brasileira NM 67: Concreto - Determinação da Consistência pelo Abatimento do Tronco de Cone (Slump Test). No item quatro Aparelhagem, a NM 67 exige algumas especificações quanto à construção de cada componente imprescindível ao teste. O molde utilizado para o corpo de prova deve ser construído com uma chapa metálica moldada em formato de um tronco de cone vazado, a união, com ou sem costura, é feita sem emendas, principalmente na parte interior, pois não pode haver protuberâncias provenientes dos elementos de união (rebites e parafusos). A dois terços da altura do cone há duas alças que auxiliam a sua elevação e, para garantir a sua estabilidade, são necessárias duas aletas localizadas na parte inferior de forma que haja total contato com a placa de base. A placa de base, de material metálico, possui perfil plano, podendo ser quadrado ou retangular. Com seção circular, a haste de compactação possui extremidades arredondadas e é feita de aço.

O item cinco da NM 67 descreve o procedimento de execução do teste. Ele deve ser realizado em amostras retiradas de todas as betoneiras, de acordo com a NM 33:94 - Concreto - Amostragem de concreto fresco. O teste inicia-se com o posicionamento do molde sobre a placa de base, ambos umedecidos previamente; a norma destaca ser de suma importância que a placa de base esteja em local plano, horizontal e sem vibrações.

Para a estabilidade do molde em relação à placa de base, o operador deve posicionar os pés nas aletas localizadas na parte inferior do molde, sendo assim, inicia-se o preenchimento com a amostra de concreto, dividindo-o em três camadas. Cada camada com aproximadamente $1 / 3$ da sua altura, deve ser golpeada 25 vezes com a haste de compactação, deve-se atentar para que a distribuição dos golpes seja uniforme e em toda a seção de cada camada e que os golpes não atinjam a camada subsequente, após todas as camadas devidamente preenchidas e compactadas, é necessário remover qualquer concreto excedente no topo do cone. Na próxima etapa é fundamental que o operador realize os procedimentos com qualidade, precisão e conforme as exigências da norma, pois, a realização dela provoca reflexos expressivos no resultado do abatimento. Essa etapa consiste na elevação do tronco de cone de forma que não ocorram interrupções, não haja torções laterais e que o tempo não exceda o intervalo de 5 a 10 segundos. O tempo total de duração do ensaio, desde a coleta da amostra até o desmolde, deve ser de 5 minutos no máximo. O cone deve ser posicionado ao lado do tronco de concreto de forma que ambos ocupem um raio de $500 \mathrm{~mm}$ entre suas extremidades. Afere-se a diferença de altura entre o eixo do tronco de concreto e o molde, esse dado indica o abatimento do concreto e é expresso em milímetros. 


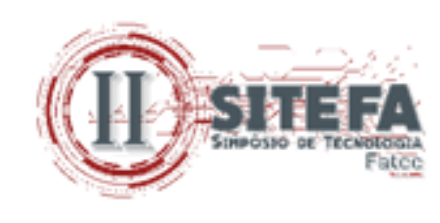

Na construção civil cada projeto se caracteriza como único, possuindo características arquitetônicas e estruturais especificas, atendendo as diversas aplicações requeridas pelo mercado. Nesse contexto o sistema produtivo se estabeleceu com técnicas manuais, devido às condições adversas de execução causadas pela má organização e dificuldade de mobilidade e armazenamento dos equipamentos no canteiro de obras. Com o advento da tecnologia e implantação do controle de qualidade houve a necessidade de adequação às exigências do mercado e, para isso, foram adotadas medidas de otimização das técnicas e dos processos através da mecanização e melhoramento de equipamentos, antes estritamente manuais. A mecanização é um processo que visa à padronização e precisão dos processos, redução do tempo de execução e gastos, além de melhores condições de segurança e trabalho, pois, reduz parcialmente a necessidade do operário em exercer força bruta. (ALVES, 2016; CIVIL; FREITAS, 2015)

Há inúmeros estudos que comprovam os benefícios da mecanização dos processos produtivos em diversas áreas. (DE OLIVEIRA et al., 2007; ELIZEU, 2007). As melhorias nos custos e tempo de produção nas áreas com implantação da mecanização não se dão apenas pelo aumento da produtividade, mas também, pela padronização, precisão e controle de qualidade que equipamentos mecanizados são capazes de fornecer. (ALVES; MANTOVANI; DE OLIVEIRA, 2006)

Em relação às condições de trabalho, sabe-se que a construção civil exige rotinas pesadas e exaustivas, as condições ambientais e do posto de trabalho muitas vezes não são favoráveis às necessidades psicofisiológicas dos trabalhadores, resultando muitas vezes em erros. Esses erros advêm de diversos fatores, como, falta de atenção devido ao cansaço, postura incorreta, ausência de iluminação satisfatória, entre outros. Todos esses fatores são estudados pela Ergonomia. A NR 17 - Ergonomia - regulamenta as condições dos trabalhadores em relação à saúde, qualidade e segurança de trabalho e consequente a melhoria da produtividade nas empresas (MEDEIROS, 2013)

Um dos temas abordados na Norma NR 17 é a postura durante a execução de tarefas, que influencia diretamente a eficiência do trabalhador. Posturas inadequadas podem causar dores e fadigas, além de stress e custos com licenças devido a doenças, o que levam à redução na produtividade e precisão da execução das tarefas (SANTANA, 1996). No teste de Abatimento do Tronco de Cone (Slump Test), estudado neste trabalho, devido ao método de execução e ao posicionamento da aparelhagem durante o processo, observou-se que a postura do operador pode influenciar diretamente no resultado.

$\mathrm{Na}$ postura mais comum observada na realização do teste a coluna do operador se apresenta flexionada e torcida. Apesar de ser um procedimento relativamente rápido, a frequência com que se realiza o teste, pois, é necessário testar amostras de todas as betonadas, pode proporcionar riscos à saúde. Além disso, esse mau posicionamento influencia o ângulo de visão do operador no ato da coleta dos dados, podendo causar erro por Paralaxe. Segundo Aurélio (2010) paralaxe significa "diferença aparente na localização de um corpo quando observado por diferentes ângulos", considerando que a medida do abatimento é feita através da leitura de uma régua graduada, o ângulo de visão do operador é de vital importância para a interpretação correta das informações. A proposta de mecanização do Teste de Abatimento de Tronco de Cone, tendo como base a problemática observada pelos autores visa trazer melhorias nos aspectos de produtividade, evitando retrabalho; de padronização, pois, não necessitará da interpretação subjetiva do operador; de precisão, pois, os conjuntos, mecânico e elétrico, apresentam elementos de alta precisão, com o intuito de reduzir os erros 


\section{(iil) $\sin \frac{1}{1}$}

operacionais; além de, melhor estruturar todo o conjunto que compõe o teste proporcionando melhorias ergonômicas.

\section{PROCEDIMENTOS METODOLÓGICOS}

Para realização desta pesquisa foi feita uma pesquisa bibliográfica a partir de material já publicado sobre o assunto pesquisado, assim como uma pesquisa documental nas normas sobre o tema. Em seguida, realizou-se a pesquisa aplicada, definida como o tipo de pesquisa que procura produzir conhecimentos para aplicação prática dirigidos à solução de problemas específicos (PRODANOVE; FREITAS, 2013).

\subsection{Métodos e materiais}

Esta seção visa apresentar o método de mecanização do teste de abatimento do tronco de cone com objetivo de padronizar e reduzir os erros operacionais. O método utilizado é composto pela adição de sistemas mecânico e elétrico.

O sistema mecânico é constituído dos seguintes componentes:

I Atuador Linear Elétrico para transmissão de movimento na elevação do cone e para movimentação da haste de compactação.

II Base que visa à ergonomia, nivelamento e transporte do teste.

III Componentes metálicos para estruturar os demais itens.

O sistema elétrico é constituído dos seguintes componentes: compactação.

I Motores de passo para acionamento dos fusos e para orientação da haste de

II Sensor de distância ultrassônico para aferir a altura do tronco de concreto.

III Microcontrolador Arduino para automação e coleta de dados.

\subsubsection{Sistemas mecânico e elétrico}

\section{Cálculos}

A norma NM 67 não específica os limites de pressão para a compactação das camadas, sendo assim, para o dimensionamento dos atuadores lineares supôs-se que a força atuante que o operador exerce ao apiloar o concreto não seja maior que a força da barra em queda livre, portanto, aplicou-se a Segunda Lei de Newton, equação (1), obtendo a força necessária.

$$
\begin{array}{ll}
F R=m * a & \\
\text { Onde: } & \\
F R & \text { Força resultante em queda livre (N) } \\
m & \text { Massa da barra (Kgf) }
\end{array}
$$

A haste de compactação fabricada em aço, tem as dimensões específicas de $\emptyset 16 \mathrm{~mm}$, $600 \mathrm{~mm}$ de comprimento e peso de $0,94 \mathrm{Kgf}$ que em queda livre possui força resultante $\mathrm{FR}=$ 9,212 N. Essa força foi utilizada como base para a seleção do atuador elétrico componente do projeto.

No dimensionamento dos dois motores utilizados, foi necessária a consideração do peso do atuador linear selecionado, que possui peso próprio de $2,42 \mathrm{Kg}$, de acordo as especificações do fabricante. Devido às características do projeto um dos motores é acoplado 


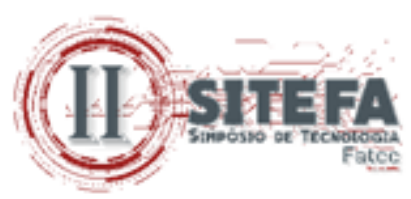

no conjunto que será acionado, portanto, adicionou-se $2 \mathrm{~kg}$ referentes ao peso do motor. $\mathrm{O}$ torque dimensionado para este motor é definido através do produto entre a distância do centro de massa e o peso total do conjunto, equação (2). Na Figura 1, tem-se o ponto exato do centro de massa e a distância onde o motor é posicionado.

$$
\tau=r * m
$$

Onde:

$\begin{array}{ll}\tau & \text { Torque (Kgf.m) } \\ r & \text { Distância (m) } \\ m & \text { Peso do conjunto (Kgf) }\end{array}$

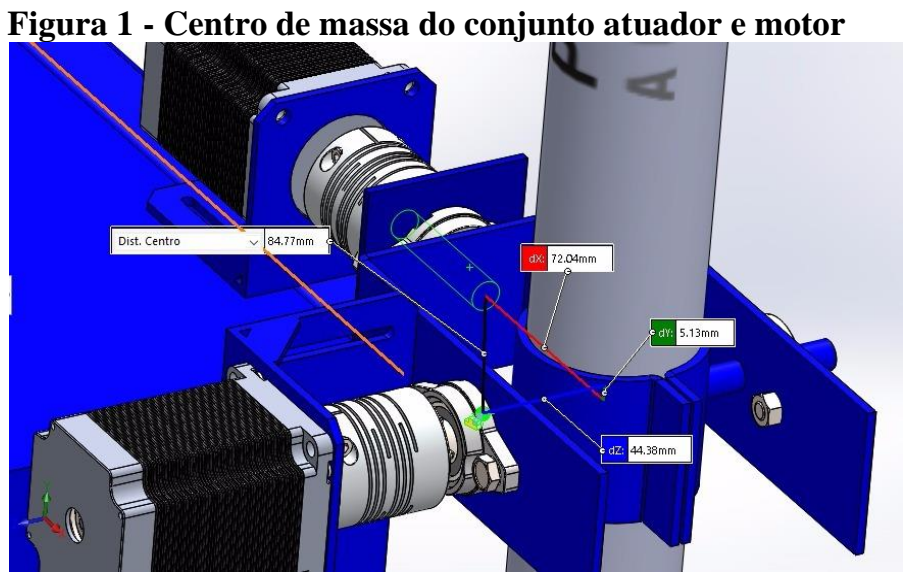

Fonte: elaborada pelos autores (2019)

O centro de massa foi obtido através do software de desenho Solidworks, utilizado para a modelagem do projeto em 3D. Sendo a massa total do conjunto igual a $5 \mathrm{Kg}$, considerando o peso do atuador, do motor e componentes de construção, e a distância do centro de massa $4,5 \mathrm{~cm}$, o torque necessário é $22,5 \mathrm{kgf.cm}$.

\section{Descrição dos componentes}

Na Figura 2 e na Figura 3 são identificados os elementos constituintes do projeto mecânico e elétrico, nesta seção também são detalhados quanto à suas especificações e utilizações.

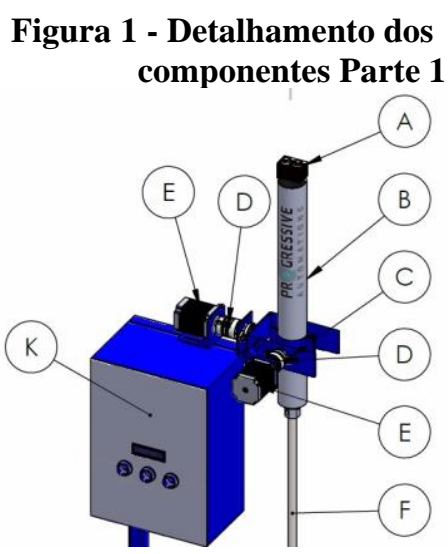

Fonte: elaborada pelos autores (2019) 


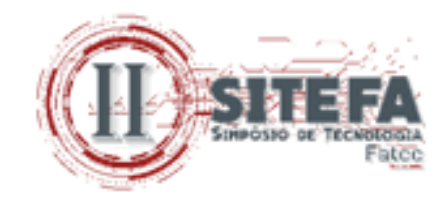

Como sistema de acionamento da haste de compactação utiliza-se um atuador linear, item B, que possui 12" de curso, força de 48,93 N com fator de segurança 5. A norma NM 67 exige que o avanço da haste não ultrapasse a camada subsequente à que está sendo compactada, portanto, o uso do atuador se torna eficaz devido à possibilidade de total controle, além disso, ele se enquadra na categoria de alta velocidade, o que é imprescindível para que o teste não ultrapasse o limite de tempo exigido na norma. $\mathrm{O}$ item $\mathrm{F}$, representa a haste de compactação que possui dimensões condizentes à norma e está fixada na extremidade do atuador.

O atuador está fixado em uma chapa metálica com seção U, onde estão localizados os mancais, item $\mathrm{C}$, que apoiam os eixos de ligação do atuador e da chapa metálica acoplados, item D, nos motores de passo NEMA 23 com torque $60 \mathrm{Kg} . \mathrm{cm}$, representados pelo item E. O item A representa o sensor ultrassônico, responsável pela aferição da altura do tronco de cone de concreto. O painel elétrico, identificado pelo item k, contém o display LCD, item $\mathrm{N}$ e os botões operacionais identificados pelo item $\mathrm{O}$. A Figura 3 a seguir, apresenta os componentes internos do painel, como fonte de 12 volts e 30 amperes, item L, microcontrolador Arduino, item M, e drivers de controle dos motores de passo, representados pelo item $\mathrm{P}$.

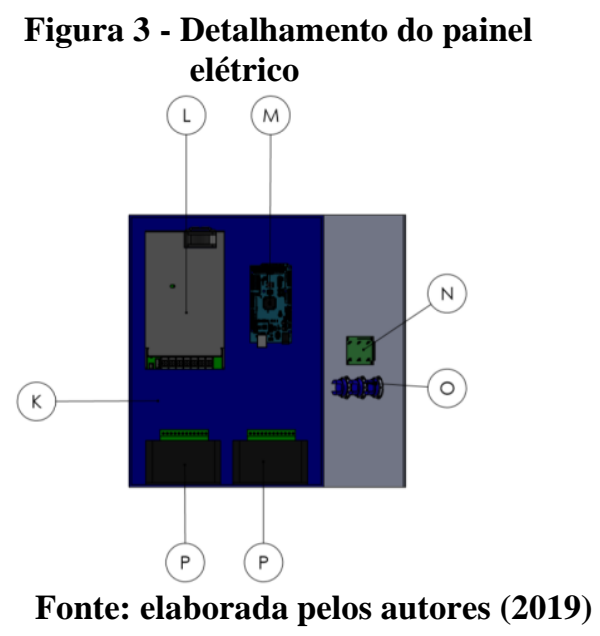

O teste normalmente é executado em canteiro de obra ou em central de concreto. Quando executado em canteiro de obra, o operador não possui total controle das condições de nivelamento, podendo haver alterações no resultado gerado pelo teste, sendo assim, desenvolveu-se uma base com indicadores de nível, localizados na parte lateral e frontal da bancada, para identificar o desalinhamento da placa de base em relação ao solo. A base é composta por uma estrutura metálica em formato de bancada que possui duas rodas e dois apoios fixos, proporciona facilidade no transporte e melhores condições de trabalho para o operador no quesito ergonômico, gerando consequências positivas que influenciam diretamente no resultado do processo. A placa de base superior, item I da Figura 4, que entra em contato com o concreto é removível, a fim de facilitar a higienização após o uso. 


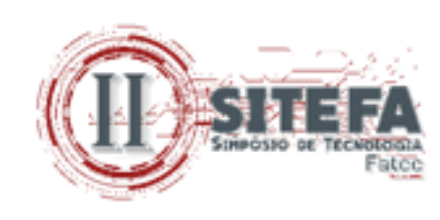

Figura 4 - Detalhamento dos componentes - Parte 2

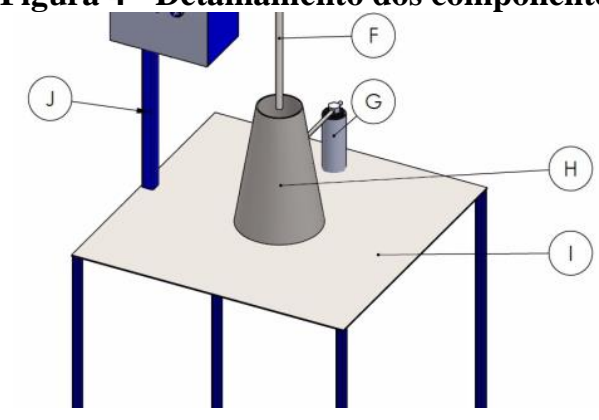

Fonte: elaborada pelos autores

$\mathrm{O}$ item $\mathrm{H}$ apresenta o molde, que é elevado por um atuador, identificado pelo item $\mathrm{G}$, com dimensões de 14" de curso, 48,93 $\mathrm{N}$ de força que supri as necessidades de velocidade, alinhamento e movimentação constante. Fixado na bancada há um perfil metálico, item J, responsável por estruturar todo o conjunto de componentes citados na Figura 2.

\section{Lógica e funcionamento do teste}

O sistema de mecanização foi elaborado para que o operador siga as diretrizes da norma NM 67 de forma facilitada, o funcionamento dos componentes é controlado pelo microcontrolador Arduino que recebe os comandos através de 3 botões principais localizados no painel elétrico, respectivamente, verde, para acionamento do conjunto superior responsável pela compactação, leitura e orientação do atuador, azul, para elevação do molde e vermelho, para casos de necessidade de cancelamento da operação. O fluxograma da Figura 5 (a), apresenta o passo a passo que será exibido no display do painel, com todas as etapas exigidas na NM 67 para a realização do teste. Os comandos acionados com base no fluxograma representado na Figura 5(a), serão transmitidos para o Arduino que controlará os componentes a fim de que todas as etapas sejam concluídas após as devidas confirmações do operador. $\mathrm{O}$ fluxograma representado na Figura 5(b) sintetiza de forma geral as operações que deverão ser executadas pelo Arduino.

Figura 2 - Fluxograma de operação do teste (a) e de funcionamento do microcontrolador (b)
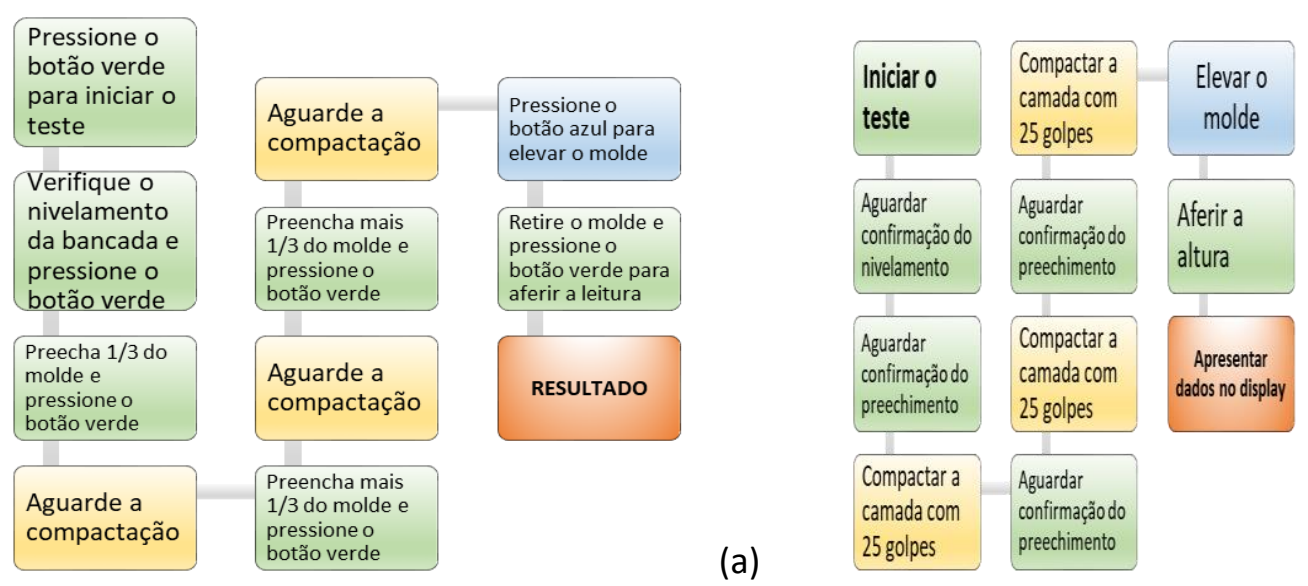

(b)

Fonte: elaborada pelos autores (2019) 


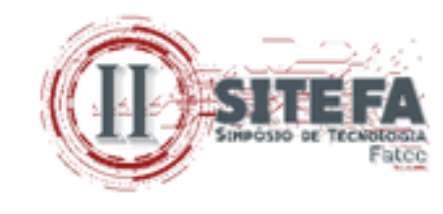

Devido a necessidade de variação de posicionamento do atuador para que efetue todas as etapas do teste, foi desenvolvido um sistema com dois motores de passo, Figura 6, posicionados à $90^{\circ}$ entre si e em relação ao conjunto do atuador e sensor ultrassônico que realizarão a compactação e a leitura dos dados, respectivamente.

\section{Figura 6 - Mecanismo de orientação}

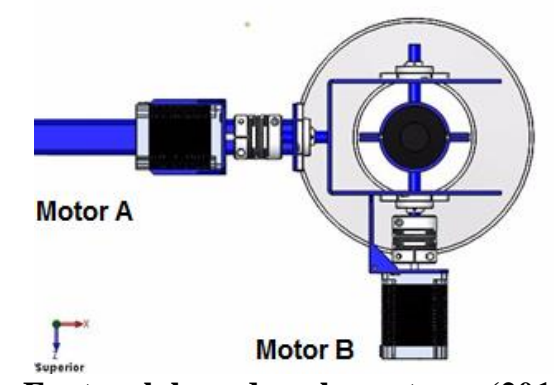

Fonte: elaborada pelos autores (2019)

O motor A indicado na Figura 7, tem a função de rotacionar o conjunto do atuador que aciona a haste de compactação em dois momentos, primeiramente posicionando-o na horizontal, a fim de que o operador tenha total acesso ao cone para preenchimento das camadas com concreto, a segunda função é a de rotação a $180^{\circ}$ da posição inicial para que o sensor ultrassônico seja ajustado sobre o tronco de concreto e realize a aferição dos dados.

Figura 7 - Posicionamento do motor A

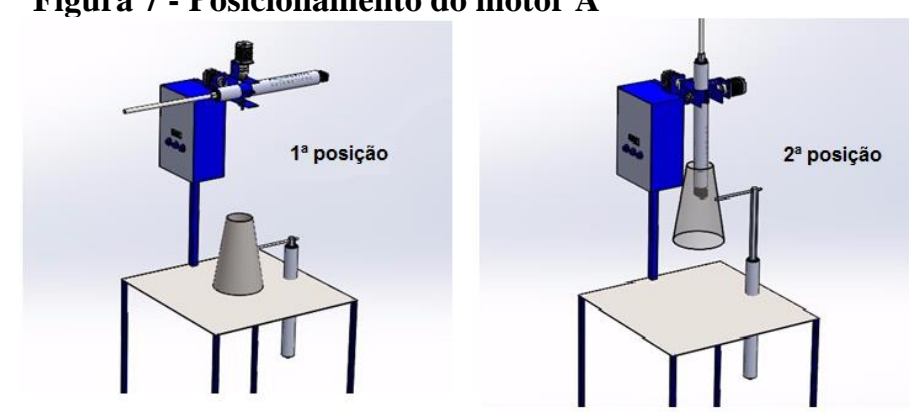

Fonte: elaborada pelos autores (2019)

Uma das partes principais do teste é o adensamento que se dá através da compactação das camadas. A norma NM 67 exige que toda a área da camada seja compactada uniformemente, sendo assim, o funcionamento em conjunto dos motores B e A visa exercer as movimentações em ângulos necessários a alcançar toda região da camada. Na Figura 8Mapeamento e simulação do movimento de compactação, são ilustrados o mapeamento das posições onde a haste deve penetrar a camada, bem como uma simulação da movimentação do conjunto haste e atuador. 


\section{(ii) $\sin$}

Figura 8 - Mapeamento e simulação do movimento de compactação

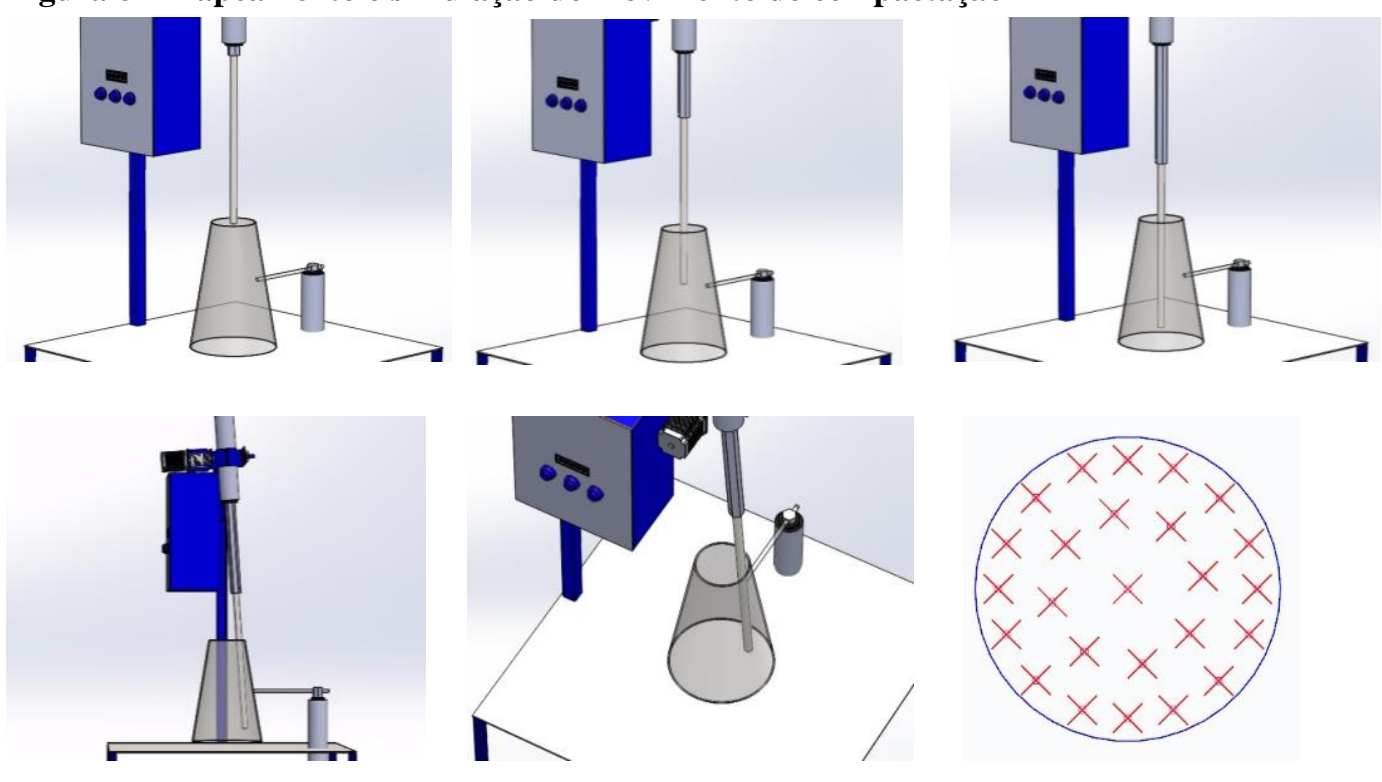

Fonte: elaborada pelos autores

\section{RESULTADOS E DISCUSSÃO}

O projeto de melhorias do Slump Test teve como principal motivação atender às queixas apresentadas por profissionais atuantes no setor da construção civil, dentre os quais projetista, empreiteiro e engenheiro responsável por uma central de concreto. Esses profissionais proporcionaram uma visão das falhas e das qualidades da realização estritamente manual do teste, bem como a importância e utilização em cada tipo de obra, seja de grande ou pequeno porte.

Dentre os principais pontos citados quanto a importância da boa execução do teste em todos os âmbitos, notou-se a necessidade da correta parametrização do abatimento do concreto, pois, dependendo do porte da obra não há a repetição do teste em canteiro, principalmente em obras menores, sendo assim, se houver alguma divergência quanto ao concreto solicitado pelo projetista e o fornecido pela central de concreto resultará em falhas de execução, prejudicando o resultado final esperado.

A mecanização proposta teve o intuito de proporcionar, principalmente, a padronização da execução do teste, pois esse processo realizado de forma manual tem variação do operador, fato que pode gerar variabilidade característica de cada operador. Sendo assim, foi proposto a utilização do atuador elétrico como simulação do manuseio da haste de compactação, ele possibilita que em todas as camadas haja a mesma força de compactação e profundidade de adensamento, além de, garantir a correto movimento de elevação do cone, devido às exigências da norma NM 67 quanto a linearidade e velocidade da elevação. Conforme ilustrado no esboço final do projeto apresentado na Figura 9. 


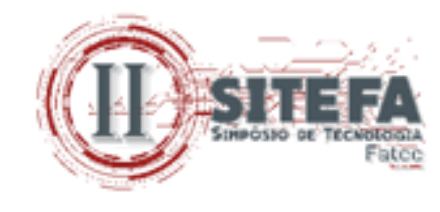

Figura 9 - Esboço final do protótipo

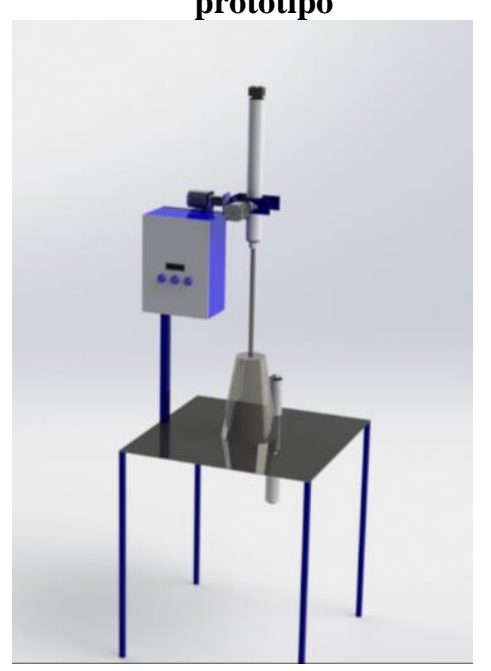

Fonte: elaborada pelos autores (2019)

O uso dos motores e sensor ultrassônico, como simulação da angulação, orientação da haste e para a aferição dos dados, respectivamente, se fez necessário para que a superfície da camada seja uniformemente compactada e não haja erros de leitura devido às questões de posicionamento e ergonomia em geral, discutidos na seção 3.3 deste trabalho. A bancada foi pensada de forma a minimizar as consequências que a má posição do operador traz à saúde com consequências na produtividade e propensão de erros de leitura.

Um dos principais focos ao projetar a mecanização do teste foi em manter as características positivas, como facilidade de operação e baixo custo. Os principais fatos que levam o Slump test manual a ser considerado de fácil aplicação é devido ao seu manuseio, facilidade na higienização, transporte e armazenamento, todas essas características foram mantidas e otimizadas com a aplicação dos recursos propostos, porém, para o cumprimento de todos estes requisitos o custo total do projeto obteve um acréscimo significativo. O principal motivo se dá, além da necessidade de incluir novos itens e sistemas, à disponibilidade no Brasil de alguns componentes, como, por exemplo, o atuador linear elétrico, com as mesmas características de qualidade e precisão. O acréscimo no custo, considerando somente os valores para aquisição dos componentes e desconsiderando valores de frete e manufatura é em média 9 vezes maior. Deve-se atentar ao fato de que a cotação se deu para a aquisição de poucas unidades de cada item, tendo em vista a produção em maior escala há possibilidade de redução do custo total de cada teste.

Contudo, considerando o elevado custo do material que depende dos resultados obtidos através do teste de abatimento, a confiabilidade dos produtos que compõem o teste é de extrema importância e o acréscimo no custo final se torna ínfimo comparado ao desperdício que pode haver caso haja erros, imprecisões e retrabalho. Os prejuízos obtidos devido a falhas operacionais põem em discussão tanto a credibilidade da central de concreto quanto a segurança final da obra, portanto, o projeto não prezou aos fatores financeiros, mas sim buscou acrescentar fatores de qualidade. 


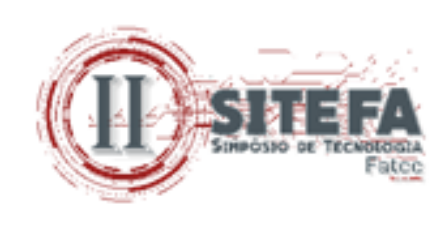

\section{CONCLUSÃO}

O projeto teve como foco o aumento da precisão e qualidade do teste de abatimento pelo tronco de cone dentro da norma regulamentadora vigente NBR NM 67: Concreto Determinação da consistência pelo abatimento do tronco de cone (Slump Test), através da técnica de mecanização das operações, antes estritamente manuais, bem como a melhoria dos fatores ergonômicos, visando a padronização e melhores condições da estação de trabalho do operador.

Portanto, foram implementados motores de passo e atuadores como simulação da movimentação realizada pelo operador, uma vez que esses componentes possuem níveis elevados de precisão e qualidade. Os erros de leitura serão reduzidos com a aplicação de sensores e circuitos de captação de dados, a fim de parametrizar a interpretação, evitando propagação de erros por subjetividade do operador. Os fatores ergonômicos, antes falhos no teste manual, foram aperfeiçoados com a implementação de bancada adequada ao processo e composição geral do sistema.

Para que todas as propostas fossem atendidas houve a necessidade de aquisição de componentes, alguns com fácil acesso, outros indisponíveis no mercado brasileiro com a qualidade e requisitos desejados, esse fato implica diretamente ao custo final do projeto, se tornando, neste caso, até 9 vezes maior que o valor de aquisição do teste manual. Entretanto, o nível de qualidade proporcionado pelo projeto de mecanização supera o fator de custo elevado, pois, a confiabilidade e precisão garantidas geram inúmeros benefícios.

Espera-se que este projeto contribua de forma singela para a área de construção civil, que inspire novas pesquisas em métodos de mecanização e automação de testes, processos e atividades cotidianas deste setor.

\section{REFERÊNCIAS}

ALVES, E.; MANTOVANI, E. C.; DE OLIVEIRA, A. J. Benefícios da mecanização da agricultura. Migração rural_urbana, agricultura familiar e novas tecnologias, p. 143, 2006.

ALVES, M. K. Industrialização na construção civil: análise da possibilidade de adoção de ações de um programa de desenvolvimento tecnológico europeu na construção civil brasileira. 2016.

ASSOCIAÇÃO BRASILEIRA DE NORMAS TÉCNICAS (ABNT). NBR 8953 - Concreto para fins estruturais - Classificação pela massa específica, por grupos de resistência e consistência. Concrete, p. 3, 2015. cone.1998, p. 8.

NBR NM 67-Concreto- Determinação da consistência pelo abatimento do tronco de

AURÉLIO, D. Significado da palavra paralaxe. 2010. Disponível em: http://www. dicionariodoaurelio.com. Acesso em: 19 jun. 2019. 


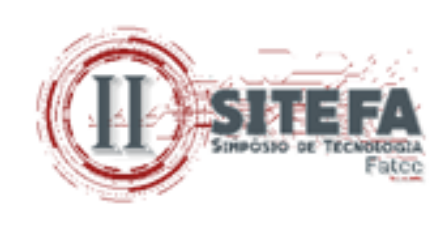

CARROMEU, C. C. et al. A importância da acreditação laboratorial e da certificação de mão de obra no controle de aceitação do Lab accreditation and manpower significance in concrete control. n. 1, p. 1-19, 2011.

CARVALHO, R. C.; DE FIGUEIREDO FILHO, J. R. Cálculo e detalhamento de estruturas usuais de concreto armado: segundo a NBR 6118: 2003. Edufscar, 2010.

CIVIL, C. D. E. E.; FREITAS, J. T. D. E. Automação na construção civil. 2015.

DE OLIVEIRA, E. et al. Custos operacionais da colheita mecanizada do cafeeiro. Pesquisa Agropecuária Brasileira, v. 42, n. 6, p. 827-831, 2007.

ELIZEU, J. Avaliação de tempo efetivo da derriça mecanizada e manual do café , na região de Garça . p. 0-5, 2007.

GAMA LINS DE ARAÚJO, T. et al. Análise das tendências da aplicação da robótica e automação na indústria da construção brasileira, 1983.

GUimarãeS, A. T. C. Propriedades do concreto fresco. Concreto: Ensino, Pesquisa e Realizações, p. 473-494, 2005.

MEDEIROS, R. I. O. M. D. E. A importância da ergonomia na construção civil. 2013.

MENIN, R. Mecanização na Construção Civil. 2012. Disponível em:

https://blogrubensmenin.com.br/mecanizacao-na-construcao-civil. Acesso em: 16 abr. 2017.

NEVILLE, A. M. Propriedades do Concreto. 5. ed. p. 912, 2015.

NEVILLE, A. M. M.; BROOKS, J. J. J. Concrete TechnologyBuilding and Environment, 2010 .

NORMA REGULAMENTADORA - NR 17 - Ergonomia. Disponível em:

http://www.guiatrabalhista.com.br/legislacao/nr/nr17.htm. Acesso em: 19 jun. 2018.

PARISOTTO, J. A. Análise de estimativas paramétricas para formular um modelo de quantificação de serviços, consumo de mão-de-obra e custos de edificações residenciais, 2003.

PRODANOV, Cleber Cristiano; FREITAS, Ernani Cesar. Metodologia do Trabalho Científico: métodos e técnicas da pesquisa e do trabalho acadêmico. 2. ed. Novo Hamburgo: Feevale, 2013.

SANTANA, A. M. C. A abordagem ergonômica como proposta para melhoria do trabalho e produtividade em serviços de alimentação. 1996.

SCHIMIDT, M. Mecanização do Canteiro de obras torna-se um importante processo na busca por produtividade. M\&T - Manutenção e Tecnologia, mar. 2015. 